\title{
Less is sometimes less
}

\author{
Thomas A. D’Amico, MD
}

\author{
From the Division of Thoracic Surgery, Department of Surgery, Duke University Medical Center, Durham, NC. \\ Disclosures: Author has nothing to disclose with regard to commercial support. \\ Received for publication Feb 18, 2018; accepted for publication Feb 22, 2018; available ahead of print April 4, \\ 2018. \\ Address for reprints: Thomas A. D'Amico MD, Section of General Thoracic Surgery, Duke University Medical \\ Center, DUMC Box 3496, Duke South, White Zone, Room 3589, Durham, NC 27710 (E-mail: thomas. \\ damico@duke.edu). \\ J Thorac Cardiovasc Surg 2018;155:2657 \\ $0022-5223 / \$ 36.00$ \\ Copyright (C) 2018 by The American Association for Thoracic Surgery \\ https://doi.org/10.1016/j.jtcvs.2018.02.053
}

Adequacy of mediastinal lymph node dissection (MLND) during resection for lung cancer is an important quality measure that is not universally met in the United States. The study by Cheng and colleagues ${ }^{1}$ in this issue of the Journal analyzes a strategy of using several pathologic variables to determine the need for MLND during resection for non-small cell lung cancer. The premise of this study is that it is an important goal in such cases to "minimize surgical trauma"; however, I believe that most surgeons would agree that there is not significant trauma related to the dissection of clinically negative lymph nodes and that the incremental trauma related to MLND is itself minimal.

In the study of Cheng and colleagues, ${ }^{1} 1430$ patients with clinical stage I non-small cell lung cancer underwent resection and MLND. Multivariable analysis demonstrated that tumor size smaller than $2 \mathrm{~cm}$, lack of $\mathrm{N} 1$ involvement, and lepidic pattern of adenocarcinoma predicted negative MLND results. Although these factors may indeed accurately predict the absence of $\mathrm{N} 2$ involvement, the intraoperative utility of these factors may be limited. Although preoperative scans may in general be accurate in the assessment of tumor size, their concordance with final pathologic determination is not uniform. In addition, the use of N1 status is similarly difficult in real time, because comprehensive frozen-section evaluation of N1 lymph nodes is not feasible. In fact, frozen-section evaluation of $\mathrm{N} 1$ nodes is not routinely performed in any resection. Finally, although the frozen-section determination of histologic subtype of non-small cell lung cancer (adenocarcinoma vs squamous cell carcinoma) is possible in most cases, the distinctions among adenocarcinoma in situ, minimally invasive adenocarcinoma, and adenocarcinoma of other various subtypes are not always perceptible, as evidenced by a concordance rate of less than $90 \%$.

Other strategies to obviate the need for MLND have been suggested. Sentinel lymph node identification has been proved unsuccessful for lung cancer; sentinel technologies do not reliably identify a single lymph node, and N2 disease may still be present even when the sentinel node is negative. In any case, that strategy was tested in an era when only dramatically.

\section{Reference}

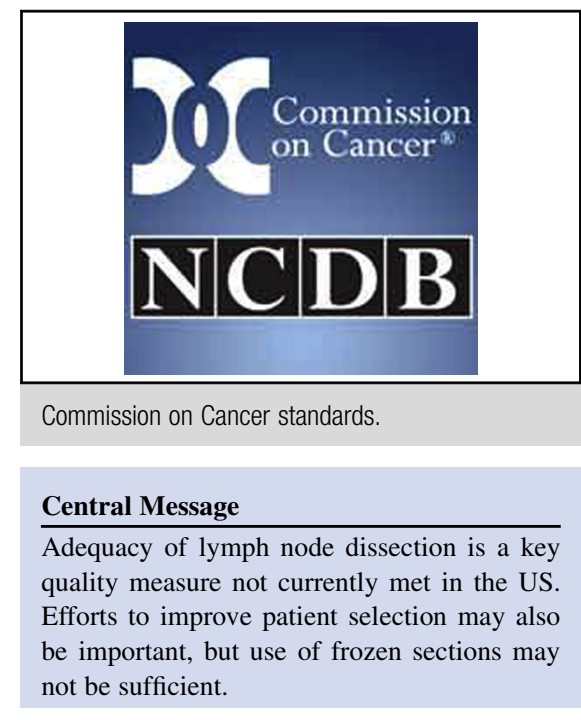

See Article page 2648.

patients with $\mathrm{N} 2$ disease could receive adjuvant chemotherapy, and the strategy was based on finding micrometastatic disease, not on limiting surgical trauma. In an era in which $\mathrm{N} 1$ disease and tumor size both direct adjuvant therapy, the effort to limit lymphadenectomy is even less useful, and this practice should be scrutinized (especially in the United States, where $30 \%$ of lung cancer resections are performed with no mediastinal lymph node sampling). Even in major cancer centers, the targets of sampling 10 lymph nodes and $3 \mathrm{~N} 2$ stations are not universally met.

Nevertheless, it is evident that not every patient with known or suspected lung cancer requires a complete MLND, and this study attempts to develop objective criteria to inform the decision-making process. Patients with slowly growing pure ground glass opacities (with high tumor disappearance ratio) are highly likely to have N0 disease, and although frozen-section analysis may confirm indolent histologic type, it may not be more accurate than a careful clinical assessment. Perhaps if surgeons were to use the proposed criteria to avoid MLND only for patients with slowly growing, pure ground glass opacities, the quality of pulmonary resection in the United States would improve

1. Cheng X, Zheng D, Li Y, Li H, Sun Y, Xiang J, et al. Tumor histology predicts mediastinal nodal status and may be used to guide limited lymphadenectomy in patients with clinical stage I non-small cell lung cancer. J Thorac Cardiovasc Surg. 2018;155:2648-56.e2. 